\title{
Classical conditioning of the rabbit nictitating membrane response can be fast or slow: Implications for Lennartz and Weinberger's (1992) two-factor theory
}

\author{
E. JAMES KEHOE and MICHAELA MACRAE \\ University of New South Wales, Sydney, Australia
}

\begin{abstract}
Classical conditioning of the rabbit's nictitating membrane (NM) response usually requires several dozen trials for the first conditioned response (CR) to appear. However, as the number of trials is reduced to one per session, the rate of acquisition increases progressively, and the first CR appears in less than a dozen trials. This large and systematic variation in the rate of conditioning challenges recent conclusions by Lennartz and Weinberger (1992). They use the rabbit NM preparation as an example of a slow-conditioning, "specific" system that is distinct from a fast-conditioning, "nonspecific" system, such as heart rate.
\end{abstract}

In this article we review experimental findings concerning the rate of acquisition in classical conditioning of the rabbit's nictitating membrane (NM) response. Specifically, this article is intended to clarify a misconception about the purportedly slow nature of acquisition in the NM preparation. This clarification is needed now, because that misconception is misleading some theorists.

Recently, Lennartz and Weinberger (1992) examined the experimental literature concerning acquisition in a variety of preparations. They concluded that there was a bimodal distribution in the rates of acquisition as measured by the number of trials to the "first consistent" conditioned response (CR). Specifically, they found that six response systems showed fast acquisition ( $M=5.7$ trials), and three response systems showed slow acquisition $(M=$ 71.3 trials). The fast systems included the galvanic skin response, conditioned suppression, blood pressure, respiration, pupil size, and heart rate. The slow systems included the NM response, the outer eyelid response, and a variety of flexion responses. According to Lennartz and Weinberger, this apparent bimodality is evidence for two conditioning processes-a rapid process for "nonspecific" CRs that are relatively independent of the type and locus of the US versus a slow process for "specific" CRs that are located near the application of the US to the subject's body.

Under a wide range of parameters in NM conditioning, several dozen trials are needed before the first CR appears. However, this portrayal of NM conditioning is incomplete. CRs can reliably appear in fewer than a dozen

Preparation of this manuscript was supported by Australian Research Council Grant AC9231222. Correspondence should be sent to E. J. Kehoe, School of Psychology, University of New South Wales, P.O. Box 1, Kensington, NSW 2033, Australia. trials when the number of pairings between the conditioned stimulus (CS) and unconditioned stimulus (US) in each training session is small. Lennartz and Weinberger (1992) controlled systematic biases by comparing the response systems for similar values of major conditioning parameters. These parameters included CS intensity, US intensity, CS-US interstimulus interval, and intertrial interval. However, trials per session as a key variable for NM conditioning was consigned to a footnote. Lennartz and Weinberger's sample of papers included only one manipulation of trials per session in NM conditioning (Kehoe \& Gormezano, 1974). Those findings were overwhelmed when averaged with all the other papers in which a large number of trials per session were used.

\section{The Effect of Trials per Session}

Data collected in four different laboratories over 20 years show clearly that the rate of acquisition for the NM response can be varied from fast to slow by manipulating the number of trials per session. Figure 1 summarizes those findings. It shows the mean number of CS-US trials to the first CR as a function of the number of trials per session for each group in the available studies (Kehoe, Cool, \& Gormezano, 1991; Kehoe \& Gormezano, 1974; Levinthal, 1973; Levinthal \& Papsdorf, 1970; Levinthal, Tartell, Margolin, \& Fishman, 1985; Salafia, Daston, \& Martino, 1976; Salafia, Terry, \& Daston, 1975). The data were plotted by using Lennartz and Weinberger's (1992) method to approximate the trial of the first CR. Specifically, they used the midpoint of the first block of trials on which the mean percentage CR exceeded $10 \%$. For example, if mean percentage CR exceeded the $10 \%$ criterion in the third block and each block contained five trials, then the value used was 12.5-the midpoint between 11 and 15. (The data from the earliest examination of trials per session [Hupka, Massaro, \& Moore, 1968] could not 


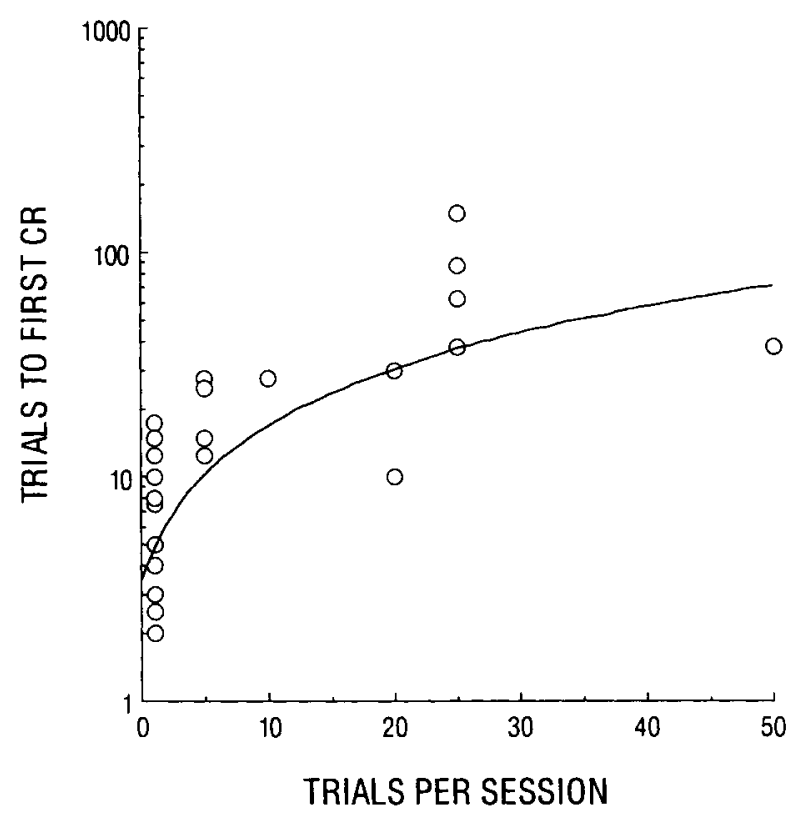

Figure 1. Trials to the first CR as a function of trials per session in the rabbit NM preparation, using the midpoint of the first block of trials exceeding $10 \%$ CRs. Each point represents the results extracted for each group in the available studies (Kehoe et al., 1991; Kehoe \& Gormezano, 1974; Levinthal, 1973; Levinthal \& Papsdorf, 1970; Levinthal et al., 1985; Salafia et al., 1976; Salafia et al., 1975).

be used, because the size of the blocks were too large for a useful approximation.) The ordinate is a log scale to more clearly expose the findings at its lower end.

Inspection of Figure 1 reveals that, for one trial per session, the first CR appears in fewer than a dozen trials. Across all of the available studies, the mean number of trials to the first CR is 7.2, with a range from 2 to 17.5 . As trials are added to a session, the number of trials required to obtain the first CR increases steadily; that is, the rate of conditioning on a trial-by-trial basis decreases in a systematic fashion. The best-fitting line for the set of means accounted for $98 \%$ of the variance. Although the log scale produces a curved line, it was in fact straight on an ordinary plot. The line had a slope of 1.35 , meaning that each extra trial per session adds 1.35 trials to the number of trials needed to reach the first $C R$.

One might be tempted to discount the rapid CR acquisition for one trial per session as aberrant. Although one trial per session is not commonly used in NM conditioning, it does not differ in any way from the more common multitrial procedures. Moreover, the change in the rate of $\mathrm{CR}$ acquisition as a function of the number of trials per session is linear in nature. This relationship implies a continuity in the underlying process between fast and slow acquisition rates for the NM response.

These systematic changes in CR acquisition are not an artifact of any changes in sensitization or pseudoconditioning across trials per session (Kehoe et al., 1991; Levinthal, 1973). For 1, 5, and 25 trials per session, groups that received unpaired presentations of the CS and US showed uniformly low levels of responding throughout training; the mean levels were less than $10 \%$. In addition, measurements taken during intertrial periods in both paired and unpaired groups showed that those levels arose from spontaneous NM closures. The negligible contribution from nonassociative sources agreed with previous observations in NM conditioning under even more massed training (Gormezano, Kehoe, \& Marshall, 1983; Gormezano, Schneiderman, Deaux, \& Fuentes, 1962).

Using Lennartz and Weinberger's (1992) scoring method, the mean number of trials to the first CR in NM studies for one trial per session is 7.2. This mean approaches the grand mean of 5.7 trials reported for nonspecific responses. Certainly, this difference of 1.5 trials is far smaller than might be expected from the grand means reported by Lennartz and Weinberger for specific responses $(M=71.3$ trials $)$ in general, and the NM response $(M=59.2)$ in particular. Thus, the rate of $C R$ acquisition for the NM response can substantially and reliably overlap the range of nonspecific systems. Moreover, NM conditioning approaches the logical limit of 2.0 trials to the first CR, which would appear only if every animal in a group showed a CR after one CS-US pairing.

What remains to be determined is how other response systems function when the number of trials per session is varied. Unfortunately, there is little data outside NM studies; a search of the literature reveals only two reports. Brimer and Dockrill (1966), using conditioned suppression, found that 1 trial per session produced faster acquisition than did 4 trials per session. Papini and Overmier (1985) found that 12 trials per session produced faster autoshaping of the pigeon's keypeck than did 48 trials per session.

\section{Implications for a Distinction Between \\ Fast and Slow Systems}

Lennartz and Weinberger (1992) concluded that the differences in the mean rate of acquisition indicate that there are " $t w o$ types of behavioral CRs"' [italics theirs]. However, the results of NM conditioning cannot be used to support that distinction for at least two reasons. First and most important, the rate of acquisition for the NM response is not invariably slow or fast; it ranges across nearly the entire dimension as a linear function of the number of trials per session. Second, averaging across NM studies is inadvertently biased toward the slow end of the dimension. This bias occurs because many trials per session are deliberately used with the knowledge that they will yield a slow rate of CR acquisition. A slow rate is often used because it is easier to (1) trace learning on a trial-by-trial basis, (2) make repeated measurements of the CR's features-for example, latency-and (3) insert nonreinforced probe trials into the training sequence without disrupting CR acquisition (e.g., Thompson, 1976). Thus, the selection of NM studies used by Lennartz and Weinberger is, at best, a random sample of experimenters' decisions to use certain acquisition rates. 
We are not denying that there are differences among response systems. The issue here is whether NM data can be used to conclude that there are two types of CRs. Hence, it is necessary to consider whether the data can be reworked to represent the differences in an unbiased fashion. Three possible ways come to mind: First, use the fastest reliable acquisition rate for each response system; second, use the number of sessions instead of the number of trials to first CR as the common dependent variable; third, use within-subject comparisons in which two or more response systems are recorded concurrently.

With regard to the fastest reliable acquisition rate, a rough indication of the size of the differences between response systems can be obtained from Lennartz and Weinberger's (1992) data tables, which reveal that the fastest reported rates for the nonspecific responses were at or near the logic limit of 2 . Specifically, the lowest recorded numbers of trials to the first $\mathrm{CR}$ for the galvanic skin response, conditioned suppression, blood pressure, respiration, pupil size, and heart rate were $2,2,4,2,3.5$, and 2 , respectively. For the specific responses-namely, the NM, flexion, and eyelid-the lowest numbers were 13,3 , and 6 , respectively. Among these, the means for the NM, and perhaps the eyelid, stand out as being different from those of the nonspecific responses. In the case of the NM response, Kehoe and Gormezano's (1974) finding is by no means the fastest known. Levinthal and his associates have consistently observed CR acquisition in the range of 2 to 8 trials under 1 trial per session (Levinthal, 1973; Levinthal \& Papsdorf, 1970; Levinthal et al., 1985 ). In any event, the difference in maximum rates between the nonspecific and specific responses amounts to only a handful of trials-a far smaller difference than the dozens of trials that are the case when the debatable practice of averaging across studies was used.

With regard to using sessions rather than trials as the unit of measurement, two reviewers of this article suggested that such a change might avoid the dilemma posed by the dramatic effect of trials per session in NM conditioning. As the number of trials per session is reduced, the number of sessions required for CR acquisition increases (Kehoe \& Gormezano, 1974). However, using sessions and ignoring trials per session imposes its own dilemma. Specifically, CR acquisition in NM conditioning can be reliably obtained in a single session if a large enough number of trials are included (Brelsford \& Theios, 1965; Scavio, 1974). Thus, acquisition of the NM response could appear to be as fast as any nonspecific response.

With regard to the use of within-subject comparisons, concurrent measurements from two or more response systems avoids all the potential confoundings in comparisons across disparate studies. Concurrent measurements in the rabbit have revealed that, in multiple-trial sessions, CRs often appear much earlier in the heart rate than in the NM response (Meredith \& Schneiderman, 1967; Vandercar \& Schneiderman, 1967; Yehle, 1968; Yehle, Spaulding, \& Lai, 1970). This difference, however, is specific to the parameters under which it appeared. It does not point necessarily to an inevitable, global difference between the heart rate and NM response, much less between the larger classes of nonspecific and specific responses. As Lennartz and Weinberger (1992) themselves note, this difference diminishes for the 250-msec CS-US interval, which is optimal for NM conditioning. The residual difference could perhaps be erased if a small number of trials were used in each session.

For purposes of neurobiology, parameter-specific differences between two concurrent responses would appear to be useful in tracing their shared or divergent pathways. For example, having different rates of acquisition may help in identifying the electrophysiological correlates of one response versus the other during training. Each response can be taken as it comes, without assuming that it represents a larger class.

For behavioral purposes, differences among responses may not be in their global rates of acquisition. Instead, the differences may be more in each response's sensitivity to the main effects and interactions among key conditioning variables such as trials per session and CS-US interval. These sorts of differences do not rule out the possibility that there are two different associative processes. However, they also do not rule out the possibilities of one, three, or many different learning processes. For example, all responses may rely on the same associative processes, but differ in their performance processes. In the rabbit, for example, the UR shows associative changes before the first CR appears (Kehoe et al., 1991). Conversely, there may be many parallel associative processes, each tuned in a different way for each response. In the case of the rabbit, the neural pathways for the heart rate and NM responses appear to diverge shortly after the inputs for the CS and US (e.g., Lavond, Lincoln, McCormick, \& Thompson, 1984; Schneiderman, McCabe, Haselton, Ellenberger, Jarrell, \& Gentile, 1987).

Lennartz and Weinberger (1992) ended their article by arguing that it would be "wrong-minded" to use any single response to represent classical conditioning and its neural underpinnings. We agree. Nevertheless, their distinction between two types of CR implies that two responses might suffice. We disagree. A two-response strategy would be equally wrong-minded, and certainly premature. Theoretical integration and theoretical distinctions rely on the continuing development of the rich, systematic, experimental database surveyed so impressively by Lennartz and Weinberger.

\section{Implications for Two-Factor Theories}

The effects of trials per session on NM conditioning challenge the use of average acquisition rates in peripheral responses as evidence for two-factor theories. These findings, however, do not challenge two-factor theories themselves. In two-factor theories of the type advocated by Lennartz and Weinberger, the key distinction is between two theoretical, associative systems, not two types of peripheral responses (cf. Konorski, 1967; Mowrer, 
1947; Schlosberg, 1937; Schneiderman, 1972). Both diffuse associations and more discrete associations are anchored only indirectly to peripheral responses. In fact, it is frequently argued that peripheral CRs depend on both associative processes. In the case of NM conditioning, at least two leading investigators have proposed that it depends on both types of association (Thompson et al., 1987; Wagner \& Brandon, 1989).

\section{REFERENCES}

Brelsford, J., JR., \& Theios, J. (1965). Single session conditioning of the nictitating membrane in the rabbit: Effect of intertrial interval. Psychonomic Science, 2, 81-82.

Brimer, C. J., Dockrill, F. J. (1966). Partial reinforcement and the CER. Psychonomic Science, 5, 185-186.

Gormezano, I., Kehoe, E. J., \& Marshall, B. S. (1983). Twenty years of classical conditioning research with the rabbit. In J. M. Sprague \& A. N. Epstein (Eds.), Progress in psychobiology and physiological psychology (pp. 197-275). New York: Academic Press.

Gormezano, I., Schneiderman, N., Deaux, E., \&uentes, C. (1962). Nictitating membrane: Classical conditioning and extinction in the albino rabbit. Science, 138, 33-34.

HupKa, R. B., Massaro, D. W., Moore, J. W. (1968). Yoked comparisons of instrumental-avoidance and classical conditioning of the rabbit nictitating membrane response as a function of interstimulus interval and number of trials per day. Psychonomic Science, 12, 93-94.

KeHoe, E. J., CoOL, V., \& Gormezano, I. (1991). Trace conditioning of the rabbit's nictitating membrane response as a function of CS-US interstimulus interval and trials per session. Learning \& Motivation, 22, 269-290.

KEHOE, E. J., \& GoRMEZANo, I. (1974). Effects of trials per session on conditioning of the rabbit's nictitating membrane response. Bulletin of the Psychonomic Society, 4, 434-436.

KoNoRsKI, J. (1967). Integrative activity of the brain: An interdisciplinary approach. Chicago: University of Chicago Press.

Lavond, D. G., Lincoln, J. S., McCormick, D. A., \& Thompson, R. F. (1984). Effects of bilateral lesions of the dentate and interpositus cerebellar nuclei on conditioning of heart-rate and nictitating membrane/eyelid responses in the rabbit. Brain Research, 305, 323-330.

LenNartz, R. C., \& WeINBerger, N. M. (1992). Analysis of response systems in Pavlovian conditioning reveals rapidly versus slowly acquired conditioned responses: Support for two factors, implications for behavior and neurobiology. Psychobiology, 20, 93-119.

LeVinThal, C. F. (1973). The CS-US interval function in rabbit nictitating membrane response conditioning: Single vs. multiple trials per conditioning session. Leaming \& Motivation, 4, 259-267.

LeVInthal, C. F., PAPSDORF, J. D. (1970). The classically conditioned nictitating membrane response: The CS-US interval function with one trial per day. Psychonomic Science, 21, 296-297.

Levinthal, C. F., Tartell, R. H., Margolin, C. M., \& Fishman, H. (1985). The CS-US interval (ISI) function in rabbit nictitating membrane response conditioning with very long intertrial intervals. Animal Learning \& Behavior, 13, 228-232.

Meredith, A. L., \&CHNeiderman, N. (1967). Heart rate and nic- titating membrane classical discrimination conditioning in rabbits under delay versus trace procedures. Psychonomic Science, 9, 139-140.

Mowrer, O. H. (1947). On the dual nature of learning: A reinterpretation of "conditioning" and "problem-solving." Harvard Educational Review, 17, 102-148.

PapinI, M. R., \& OVermier, J. B. (1985). Partial reinforcement and autoshaping of the pigeon's key-peck behavior. Learning \& Motivation, 16, 109-123.

Salafia, W. R., Daston, A. P., \& Martino, L. J. (1976). Conditioning of the rabbit (Oryctolagus cuniculus) nictitating membrane response as a function of trials per session and ISI with a short intersession interval. Bulletin of the Psychonomic Society, 7, 343-344.

Salafia, W. R., Terry, W. S., \& Daston, A. P. (1975). Conditioning of the rabbit (Oryctolagus cuniculus) nictitating membrane response as a function of trials per session, ISI, and ITI. Bulletin of the Psychonomic Society, 6, 505-508.

SCAvio, M. J., JR. (1974). Classical-classical transfer: Effects of prior aversive conditioning upon appetitive conditioning in rabbits (Oryctolagus cuniculus). Journal of Comparative \& Physiological Psychology, 88, 107-115.

SCHLOSBERG, H. (1937). The relationship between success and the laws of conditioning. Psychological Review, 44, 379-394.

Schneiderman, N. (1972). Response system divergencies in aversive classical conditioning. In A. H. Black \& W. F. Prokasy (Eds.), Classical conditioning: Current theory and research (pp. 341-376). New York: Appleton-Century-Crofts.

Schneiderman, N., McCabe, P. M., Haselton, J. R., Ellenderger, H. H., JARrell, T. W., \& Gentile, C. G. (1987). Neurobiological bases of conditioned bradycardia in rabbits. In I. Gormezano, W. F. Prokasy, \& R. F. Thompson (Eds.), Classical conditioning (pp. 37-63). Hillsdale, NJ: Erlbaum.

Thompson, R. F. (1976). The search for the engram. American Psychologist, 31, 209-227.

Thompson, R. F., Donegan, N. H., Clark, G. A., Lavond, D. G., Lincoln, J. S., Madden, J., Mamounas, L. A., Mauk, M. D., \& McCormick, D. A. (1987). Neuronal substrates of discrete, defensive conditioned reflexes, conditioned fear states, and their interactions in the rabbit. In I. Gormezano, W. F. Prokasy, \& R. F. Thompson (Eds.), Classical conditioning (pp. 371-399). Hillsdale, NJ: Erlbaum.

VANDERCAR, D. H., \& SCHNEIDERMAN, N. (1967). Interstimulus interval functions in different response systems during classical discrimination conditioning of rabbits. Psychonomic Science, 9, 9-10.

WAGNER, A. R., \& Brandon, S. E. (1989). Evolution of a structured connectionist model of Pavlovian conditioning (AESOP). In S. B. Klein \& R. R. Mowrer (Eds.), Contemporary learning theories: Pavlovian conditioning and the status of traditional learning theory (pp. 149190). Hillsdale, NJ: Erlbaum.

YeHLE, A. L. (1968). Divergencies among rabbit response systems during three-tone classical discrimination conditioning. Journal of $E x$ perimental Psychology, 77, 468-473.

Yehle, A. L., SPaulding, L. E., \& LAi, H.-Y. (1970). Classical discrimination conditioning and reversal in the albino rabbit. Psychonomic Science, 20, 187-188.

(Manuscript received October 19, 1992; revision accepted for publication October 5,1993 .) 